\title{
Comparison of keratometric and pachymetric parameters with Scheimpflug imaging in normal and keratoconic Asian eyes
}

This article was published in the following Dove Press journal:

Clinical Ophthalmology

12 November 2014

Number of times this article has been viewed

\author{
Hou-Boon Lim' \\ Gavin S Tan' \\ Li Lim' \\ Hla Myint Htoon ${ }^{2}$ \\ 'Singapore National Eye Centre, \\ Singapore; ${ }^{2}$ Singapore Eye Research \\ Institute, Singapore
}

Purpose: To evaluate the keratometric and pachymetric parameters of keratoconic corneas of Asian eyes with the Scheimpflug imaging camera.

Patients and methods: This is a cross-sectional study of 22 eyes with Amsler-Krumeich stage 1 keratoconus and 48 eyes from normal subjects conducted in a tertiary eye hospital. A rotating Scheimpflug imaging system, the Pentacam, was used to evaluate all eyes for tomographic parameters, as well as pachymetric progression indices (PPI) and Ambrósio relational thickness (ART).

Results: All PPI and ART parameter values were significantly different between study and control groups. Cornea minimum radius of curvature, absolute distance from corneal apex to thinnest location, as well as the distance from corneal apex to thinnest location in $\mathrm{Y}$-axis also demonstrated statistically significant differences. The mean ART values for keratoconus eyes were $241 \mu \mathrm{m}$ (ART-maximum) and $352 \mu \mathrm{m}$ (ART-average), falling within previously reported best cutoff values for detecting keratoconus. On receiver operating characteristics curve analysis, the area under the curve values were highest for PPI and ART parameters.

Conclusion: There are significant differences in tomographic parameters between stage 1 keratoconic and normal Asian eyes. Pachymetric indices such as the PPI and the ART index can serve as additional tools in differentiating keratoconic from normal eyes. The findings validate the usefulness of the ART in identifying keratoconic eyes in Asians.

Keywords: keratoconus, pentacam, corneal tomography, Ambrósio relational thickness

\section{Introduction}

Keratoconus is a progressive corneal ectatic disorder that may have a variable expression in early stages, with subtle signs and borderline abnormal features that are difficult to detect. ${ }^{1-3}$ Corneal topography represented a true revolution in the diagnosis and management of corneal diseases like keratoconus as it could detect subtle changes on the anterior corneal surface prior to loss of corrected distance visual acuity and the development of typical slit-lamp microscopy findings. ${ }^{4-7}$

Topography measurement by Placido reflection, however, was limited exclusively to the anterior corneal surface. Slit-imaging technology was an improvement in corneal imaging, as it could not only measure the anterior corneal surface but also the posterior surface, and was able to define the spatial relationship between the two, and to characterize corneal architecture in three dimensions. This reconstruction of the cornea provides more information, greatly enhancing the sensitivity and specificity for detecting ectasia. Ambrósio and Belin ${ }^{8}$ have previously proposed the term "tomography" to better reflect the three-dimensional characterization of the cornea instead of surface "topography".
Correspondence: Li Lim

Singapore National Eye Centre, II Third Hospital Avenue, I6875I, Singapore

Tel +65 62277255

Email lim.li@snec.com.sg 
Using the Pentacam, a rotating Scheimpflug imager, Ambrósio et $\mathrm{al}^{9}$ have previously reported on the use of pachymetric progression indices (PPI) and the concept of relational thickness in differentiating keratoconic and normal corneas compared with single-point thickness values. In particular, the study demonstrated that Ambrósio relational thickness (ART) parameters had the best receiver operating characteristics (ROC) as a test, and ART cutoffs for keratoconic eyes were determined.

Following the work of Ambrósio et al ${ }^{8,9}$ few other studies have evaluated the findings in an Asian population. ${ }^{10,11}$ The purpose of this study is thus to analyze the keratometric and pachymetric properties of keratoconic corneas of Asian eyes with the Scheimpflug imaging camera, and to study the usefulness of ART and PPI in differentiating keratoconus from normal eyes.

\section{Materials and methods}

This study adhered to the tenets of the Declaration of Helsinki and was approved by the Ethics Committee of the Singhealth Centralised Institutional Review Board. All patients included in the study provided informed consent.

Cases in the keratoconic group were selected from a prospective study on collagen cross-linking for keratoconus. Inclusion criteria included visual acuity with contact lenses better than or equal to $6 / 12(20 / 40)$, good general health, and age of more than 18 years. Patients with eyes that met the Amsler-Krumeich criteria ${ }^{12}$ for stage 1 keratoconus (eccentric steepening, absence of any corneal scarring, myopia, and astigmatism $<5.00 \mathrm{D}$ and mean keratometry $<48.0 \mathrm{D}$ ) were included in this study. In patients with both eyes that met the inclusion criteria, one of the eyes was randomly selected for analysis.

Control cases were selected from a database of candidates for refractive surgery with normal corneas and myopia or myopic astigmatism. Eyes were considered normal if they had no ocular pathology, no previous ocular surgery, and no irregular corneal pattern on corneal tomography. One eye was randomly selected from each candidate for inclusion in this study.

Exclusion criteria included a history of corneal surgery, significant corneal scarring, and significant ophthalmic disease that may potentially affect the outcomes.

All eyes had a comprehensive ocular examination as well as rotating Scheimpflug corneal tomography (Pentacam; Oculus. Wetzlar, Germany). Patients that were using contact lenses were asked to discontinue use for at least 1 week before the topographic examination. During Pentacam examination, subjects were positioned at the instrument with proper placement on the chin rest and forehead strap and asked to blink a few times before looking with both eyes at the fixation target. With proper alignment achieved, all participants underwent scanning according to a standardized protocol. Only cases with acceptable-quality images were included in the study.

The following anterior and posterior corneal surface parameters were evaluated with the Pentacam: corneal keratometry power in the flattest meridian in the $3.0 \mathrm{~mm}$ central zone, corneal keratometry power in the steepest meridian in the $3.0 \mathrm{~mm}$ central zone, mean central keratometry in the $3.0 \mathrm{~mm}$ zone, and mean astigmatism in the $3.0 \mathrm{~mm}$ central zone. The minimum radius of corneal curvature was also measured.

The central corneal thickness at the apex (geometric center of the examination), central corneal thickness at the pupil center, and the minimum corneal thickness at the thinnest point were recorded. Also, the vertical, horizontal, as well as the distances from the cornea apex to the point of the thinnest corneal location were determined.

The Pentacam calculates a PPI for every $1^{\circ}$ meridian along the complete $360^{\circ}$, starting at the thinnest point. The average of all meridians and the ones with lowest and highest values are presented. The pachymetric index will be higher if the cornea gets thicker in a more accentuated pattern from the thinnest point out to the periphery. The average, minimum, and maximum PPIs were recorded.

ART was calculated by the following formulae:

$$
\begin{aligned}
\text { Average ART }(\text { ART-Avg })= & \text { minimum corneal } \\
& \text { thickness } / \text { average PPI }
\end{aligned}
$$

Maximum ART $($ ART-Max $)=$ minimum corneal thickness/maximum PPI

Statistical analysis was performed using SPSS software (version 11.0; SPSS Inc., Chicago, IL, USA). The data were not normally distributed; therefore, the non-parametric Mann-Whitney $U$-test (Wilcoxon rank sum test) was used to compare each parameter between two groups. A $P$-value of less than 0.05 was considered statistically significant. ROC curves ${ }^{13}$ were used to determine the overall predictive accuracy of the parameters when used as a test to identify eyes with keratoconus. The area under these curves ${ }^{14}$ (AUC) measure discrimination; that is, the ability of the test to correctly classify eyes with and without disease. An area of 1.0 represents a perfect test while an area of 0.5 represents a worthless test. 
Table I Keratometric, pachymetric, and pachymetric progression indices of study groups

\begin{tabular}{|c|c|c|c|c|}
\hline Parameter & $\begin{array}{l}\text { Keratoconus eyes, } \\
\text { mean }(S D)(n=22)\end{array}$ & $\begin{array}{l}\text { Normal eyes, } \\
\text { mean }(\mathrm{SD})(\mathrm{n}=48)\end{array}$ & $\begin{array}{l}\text { P-value } \\
\text { (Mann-Whitney U) }\end{array}$ & $\begin{array}{l}\text { Mean difference } \\
(95 \% \mathrm{Cl})\end{array}$ \\
\hline Central keratometry flat axis, D & $42.99(2.2)$ & $42.6(1.3)$ & 0.658 & $0.35(-0.49,1.19)$ \\
\hline Central keratometry steep axis, $D$ & $44.6(2.7)$ & $44.0(1.3)$ & 0.455 & $0.54(-0.42,1.49)$ \\
\hline Mean central keratometry, D & $43.7(2.1)$ & $43.3(1.3)$ & 0.29 & $0.40(-0.4 \mathrm{I}, 1.22)$ \\
\hline Central astigmatism, $D$ & $2.25(1.9)$ & I.4 (0.7) & 0.173 & $0.84(0.22,1.5)$ \\
\hline Cornea minimum radius of curvature, $\mathrm{mm}$ & $7.09(0.59)$ & $7.39(1.1)$ & 0.001 & $-0.3(-0.78,1.75)$ \\
\hline Pachymetry apex, $\mu \mathrm{m}$ & $532.3(38.9)$ & $533.4(28.2)$ & 0.766 & $-1.2(-17.6,15.2)$ \\
\hline Pachymetry thinnest location, $\mu \mathrm{m}$ & $518.8(39.9)$ & $528.85(27.85)$ & 0.475 & $-10.04(-26.5,6.4)$ \\
\hline Pachymetry pupil center, $\mu \mathrm{m}$ & $535.9(39.87)$ & $534.1(28.02)$ & 0.578 & $1.81(-14.7,18.3)$ \\
\hline Thinnest location distance from apex in $\mathrm{X}$ axis, $\mathrm{mm}$ & $0.46(0.3)$ & $0.42(0.23)$ & 0.800 & $0.04(-0.09,0.17)$ \\
\hline Thinnest location distance from apex in $\mathrm{Y}$ axis, $\mathrm{mm}$ & $0.87(0.35)$ & $0.53(0.26)$ & $<0.001$ & $0.34(0.19,0.49)$ \\
\hline Thinnest location absolute distance from apex, $\mathrm{mm}$ & $1.01(0.38)$ & $0.73(0.19)$ & 0.001 & $0.28(0.15,0.42)$ \\
\hline Pachymetric progression index, min & $0.94(0.33)$ & $0.58(0.14)$ & $<0.001$ & $0.36(0.25,0.48)$ \\
\hline Pachymetric progression index, avg & $1.47(0.47)$ & $0.94(0.15)$ & $<0.001$ & $0.52(0.38,0.67)$ \\
\hline Pachymetric progression index, $\max$ & $2.15(0.86)$ & I.31 (0.22) & $<0.001$ & $0.837(0.57, \mathrm{I} . \mathrm{I})$ \\
\hline Ambrósio relational index, avg & $390.6(134.5)$ & $576.0(111.7)$ & $<0.001$ & $-185.4(-246.7,-124.2)$ \\
\hline Ambrósio relational index, max & $279.3(106.9)$ & $418.9(97.2)$ & $<0.001$ & $-139.7(-191.2,88.2)$ \\
\hline
\end{tabular}

Abbreviations: avg, average; $\mathrm{Cl}$, confidence interval; max, maximum; min, minimum; SD, standard deviation; $\mathrm{n}$, number of eyes.

\section{Results}

The keratoconus group comprised 22 eyes, while the control group consisted of 48 eyes. The mean age of study subjects was 29.4 \pm 7.9 (standard deviation [SD]) years, while that of the control group was $31.0 \pm 9.2$ (SD) years. The difference in mean ages was not statistically significant $(P=0.23)$. Of the study subjects, $82.8 \%$ were males. Racially, the study group was constituted of Chinese (66.6\%), Malays (12.1\%), Indians (12.1\%), and Eurasians (9.0\%).

\section{Rotating Scheimpflug imaging}

Table 1 shows the mean tomographic, PPI, and ART values in both groups. Of note, while most tomographic readings did not show significant differences between the study and control groups, all PPI and ART values indicated significant differences. PPIs were higher in keratoconic eyes, while ART indices were lower.

Cornea minimum radius of curvature, absolute distance from the corneal apex, as well as the distance from corneal apex in Y-axis were also significantly different between study and control groups.

\section{ART}

The mean ART values for the normal group were 404 and $563 \mu \mathrm{m}$ for ART-Max and ART-Avg, respectively. In the keratoconus group, the mean values were 241 and $352 \mu \mathrm{m}$ for ART-Max and ART-Avg, respectively. Table 2 shows the mean ART values of normal and keratoconic eyes in the present study, as well as the best cutoff values as reported by Ambrósio et $\mathrm{al}^{9}$ for eyes with keratoconus and susceptibility for ectasia.

\section{ROC curve analysis}

Table 3 shows the results of the ROC curve analysis AUC, 95\% confidence intervals, and significance levels for each parameter tested in keratoconus and normal groups. In discriminating keratoconus from control eyes, PPI and ART produced high AUC values, indicating good diagnostic performance when used as a test. While the means of cornea minimum radius of curvature, absolute distance from the corneal apex, as well as the distance from corneal apex in $\mathrm{Y}$-axis were significantly different between the two groups, their lower AUCs meant that using these parameters

Table 2 Mean ART indices in comparison with cutoff values previously reported by Ambrósio et al

\begin{tabular}{|c|c|c|c|c|}
\hline & \multicolumn{2}{|l|}{ Present study } & \multicolumn{2}{|c|}{ Previously reported best cutoff } \\
\hline & $\begin{array}{l}\text { Keratoconus eyes, } \\
\text { mean }\end{array}$ & $\begin{array}{l}\text { Normal eyes, } \\
\text { mean }\end{array}$ & $\begin{array}{l}\text { Cutoff for keratoconus } \\
\text { eyes }\end{array}$ & $\begin{array}{l}\text { Cutoff for detecting ectasia } \\
\text { susceptibility }\end{array}$ \\
\hline ART-Max, $\mu \mathrm{m}$ & $24 I$ & 404 & 339 & 391 \\
\hline ART-Avg, $\mu \mathrm{m}$ & 352 & 563 & 424 & 512 \\
\hline
\end{tabular}

Note: Data from Ambrósio et al. ${ }^{9}$

Abbreviations: ART, Ambrósio relational thickness; Avg, average; Max, maximum. 
Table 3 Summary of characteristics of ROC of Pentacam parameters obtained

\begin{tabular}{llll}
\hline Parameter & AUC & $\mathbf{9 5 \%} \mathbf{C l}$ & P-value \\
\hline Pachymetric progression index - Average & 0.880 & $0.788,0.972$ & $<0.00 I$ \\
Pachymetric progression index - Minimum & 0.849 & $0.751,0.947$ & $<0.00 I$ \\
Pachymetric progression index - Maximum & 0.845 & $0.744,0.946$ & $<0.00 I$ \\
Ambrósio relational index - Average & 0.865 & $0.762,0.968$ & $<0.00 I$ \\
Ambrósio relational index - Maximum & 0.832 & $0.724,0.94 I$ & $<0.00 I$ \\
Thinnest location distance from apex in Y axis, mm & 0.775 & $0.655,0.895$ & $<0.00 I$ \\
Thinnest location absolute distance from apex, mm & 0.741 & $0.598,0.884$ & $0.00 I$ \\
Central astigmatism, D & 0.602 & $0.439,0.764$ & 0.174 \\
\hline
\end{tabular}

Abbreviations: $\mathrm{AUC}$, area under the curve; $\mathrm{Cl}$, confidence interval; $\mathrm{ROC}$, receiver operating curves.

to test for keratoconus would result in poor diagnostic performances. The ROC curves of these parameters can be seen in Figure 1.

Pairwise comparisons between each different parameter's AUC, using the Hanley-McNeil method, ${ }^{14}$ are shown in Table 4. Of note, no statistically significant difference was found between the ART and PPI indices.

\section{Discussion}

In this study, keratometric, pachymetric, as well as novel thickness metrics from Pentacam tomography are presented and evaluated in normal and keratoconic Asian eyes.

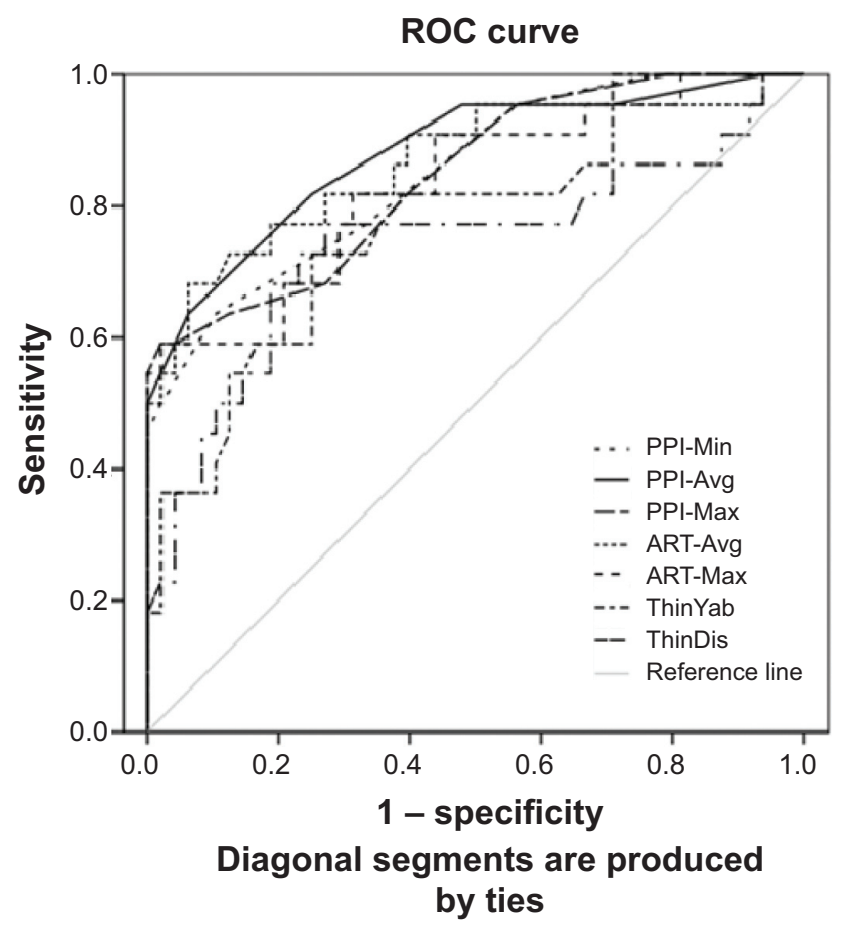

Figure I Combined ROC for ART-Avg, ART-Max, PPI-Min, PPI-Avg, and PPI-Max. Also included are Thin Yab and ThinDis.

Abbreviations: ART, Ambrósio relational thickness; ART-Avg, average ART; ART-Max, maximum ART; PPI-Avg, average pachymetric progression index; PPI-Max, maximum pachymetric progression index; PPI-Min, minimum pachymetric progression index; ROC, receiver operating curves; ThinDis, thinnest location absolute distance from apex; Thin Yab, thinnest location distance from apex in $Y$ axis.
Significant differences in these parameters have been found between normal and study eyes, in line with published reports on Latin American and Middle Eastern populations., ${ }^{9,15}$

In terms of diagnostic performance, the PPI and ART parameters produced the highest AUCs amongst all the other parameters. Ambrósio et $\mathrm{al}^{9}$ previously reported that the best AUCs were produced by ART-Avg (0.987), ART-Max (0.983) followed by PPI-average (0.980). Interestingly, in this study, PPI-average returned the highest AUC (0.880), followed by ART-Avg (0.865) and PPI-minimum (0.849). However, pairwise comparisons did not show any significant difference between any of these parameters.

Comparing against the ART-Avg and ART-Max cutoffs previously reported by Ambrósio et $\mathrm{al}^{9}$ for the identification of keratoconic eyes (Table 3), the mean ART-Avg and ARTMax values found in the study group fell below the cutoff values. Similarly, the mean ART-Avg and ART-Max values found in the control group were above the cutoff values for detecting eyes with ectasia susceptibility. These findings support the use of these Pentacam indices for the evaluation of stage 1 keratoconus in Asian eyes.

There are several limitations in the present study. The sample size of the study group is relatively small. As such, while the results validate the usefulness of the Pentacam in differentiating keratoconic from normal eyes in Asians as a group, the sample size is too small to establish population norms for the measured parameters. There was also a higher proportion of males than females in the study group. However, there is no current evidence of differing clinical presentations of keratoconus between male and female patients, and thus, this is unlikely to skew the results of this study.

In a recent study conducted by Ruisenor Vazquez et a ${ }^{16}$ in a non-Asian population, Pentacam Scheimpflug imaging tomography was found to be able to detect most subclinical keratoconus cases with unremarkable topography. AUC values obtained for PPI and ART indices were mostly higher than in the current study, ranging from 0.79 to 0.93 . 
Table 4 Pairwise comparisons of ROC (AUC) using Hanley and McNeil's method

\begin{tabular}{|c|c|c|c|c|c|c|c|}
\hline & PPI-Min & PPI-Max & ART-Avg & ART-Max & $\begin{array}{l}\text { Thinnest location } \\
\text { distance from apex } \\
\text { in } Y \text { axis }\end{array}$ & $\begin{array}{l}\text { Thinnest location } \\
\text { absolute distance } \\
\text { from apex }\end{array}$ & $\begin{array}{l}\text { Central } \\
\text { astigmatism }\end{array}$ \\
\hline PPI-Avg & 0.371 & 0.305 & 0.416 & 0.208 & 0.101 & 0.062 & 0.0007 \\
\hline PPI-Min & & 0.936 & 0.699 & 0.763 & 0.278 & 0.164 & 0.0039 \\
\hline PPI-Max & & & 0.591 & 0.478 & 0.302 & 0.145 & 0.0039 \\
\hline ART-Avg & & & & 0.334 & 0.185 & 0.115 & 0.001 \\
\hline ART-Max & & & & & 0.409 & 0.214 & 0.007 \\
\hline $\begin{array}{l}\text { Thinnest location distance } \\
\text { from apex in } Y \text { axis }\end{array}$ & & & & & & 0.485 & 0.086 \\
\hline $\begin{array}{l}\text { Thinnest location absolute } \\
\text { distance from apex }\end{array}$ & & & & & & & 0.189 \\
\hline
\end{tabular}

Abbreviations: ART, Ambrósio relational thickness; AUC, area under the curve; Avg, average; Max, maximum; Min, minimum; PPI, pachymetric progression index; ROC, receiver operating curves.

However, test specificity was highlighted as an issue, as up to $10 \%$ of subclinical keratoconus cases may be undetected by such evaluation.

Using the Pentacam, Bae et $\mathrm{al}^{17}$ evaluated topographic and tomographic changes in fellow eyes of Asian patients with unilateral keratoconus to compare them with normal eyes. Previous research indicates that true unilateral keratoconus is very rare, and thus the normal fellow eye may be the ideal model for the mildest form of subclinical keratoconus. The group found that fellow eyes in unilateral keratoconus patients showed differences in several parameters that were not detectable with the Pentacam detection program. However, to be used as a test, each single parameter alone was not sufficient to detect these early changes.

The inclusion criteria for the current study included patients who have stage 1 keratoconus. Pentacam indices derived in this study are thus from clinically detectable keratoconus. As a test, it might be more useful if these were based on early or forme fruste keratoconus so that they can be detected even when not manifested clinically. Nonetheless, the current study supports the findings previously reported on the usefulness of Scheimpflug imaging in assessing keratoconic eyes. In order to develop it further into a deployable early detection tool, further studies will be needed to both determine its test performance as well as establish cutoff values for Asian eyes.

\section{Conclusion}

This study demonstrated significant differences in keratometric and pachymetric parameters between stage 1 keratoconic and normal corneas in Asians. Pachymetric indices such as the PPI and the ART indices are useful tools for detecting keratoconus in this population. The findings also support the previously reported findings of the usefulness of the ART in identifying keratoconus.

\section{Disclosure}

The authors have no competing/conflicting interests to declare. This research was funded by the Health Research Endowment Fund of the Singapore Ministry of Health. The protocol for this study adheres to the tenets of the Declaration of Helsinki and was approved by the Ethics Committee of the Singhealth Centralised Institutional Review Board. All patients included in the study provided informed consent, and patient anonymity was preserved.

\section{References}

1. Rabinowitz YS. Major review - keratoconus. Surv Ophthalmol. 1998; 42:297-319.

2. Saad A, Gatinel D. Topographic and tomographic properties of forme fruste keratoconus corneas. Invest Ophthalmol Vis Sci. 2010;51:5546-5555.

3. Klyce SD. Chasing the suspect: keratoconus [editorial]. Br J Ophthalmol. 2009;93:845-847.

4. Wilson SE, Ambrósio R. Computerized corneal topography and its importance to wavefront technology. Cornea. 2001;20(5):441-454.

5. Ambrósio R Jr, Klyce SD, Wilson SE. Corneal topographic and pachymetric screening of keratorefractive patients. J Refract Surg. 2003; 19(1):24-29.

6. Maguire LJ, Bourne WM. Corneal topography of early keratoconus. Am J Ophthalmol. 1989;108(2):107-112.

7. Maeda N, Klyce SD, Tano Y. Detection and classification of mild irregular astigmatism in patients with good visual acuity. Surv Ophthalmol. 1998;43(1):53-58.

8. Ambrósio R, Belin MW. Imaging of the cornea: topography vs tomography. J Refract Surg. 2010;26(11):847-849.

9. Ambrósio R, Caiado ALC, Guerra FP, et al. Novel pachymetric parameters based on corneal tomography for diagnosing keratoconus. J Refract Surg. 2011;27:753-758.

10. Abolbashari F, Mohidin N, Ahmadi Hosseini SM, Mohd Ali B, Retnasabapathy S. Anterior segment characteristics of keratoconus eyes in a sample of Asian population. Cont Lens Anterior Eye. 2013; 36(4):191-195.

11. Ahmadi Hosseini SM, Mohidin N, Abolbashari F, Mohd-Ali B, Santhirathelagan CT. Corneal thickness and volume in subclinical and clinical keratoconus. Int Ophthalmol. 2013;33(2):139-145.

12. Krumeich JH, Daniel J, Knülle A. Live-epikeratophakia for keratoconus. J Cataract Refract Surg. 1998;24(4):456-463.

13. McNeil BJ, Hanley JA. Statistical approaches to the analysis of receiver operating characteristic (ROC) curves. Med Decis Making. 1984;4(2):137-150. 
14. Hanley JA, McNeil BJ. The meaning and use of the area under a receiver operating characteristic (ROC) curve. Radiology. 1982;143(1): 29-36.

15. Muftuoglu O, Ayar O, Ozulken K, Ozyol E, Akıncı A. Posterior corneal elevation and back difference corneal elevation in diagnosing forme fruste keratoconus in the fellow eyes of unilateral keratoconus patients. J Cataract Refract Surg. 2013;39(9):1348-1357.
16. Ruisenor Vazquez PR, Galletti JD, Minguez N, et al. Pentacam Scheimpflug tomography findings in topographically normal patients and subclinical keratoconus cases. Am J Ophthalmol. 2014;158(1):32-40.e2.

17. Bae GH, Kim JR, Kim CH, Lim DH, Chung ES, Chung TY. Corneal topographic and tomographic analysis of fellow eyes in unilateral keratoconus patients using Pentacam. Am J Ophthalmol. 2014;157(1): 103-109.e1.

\section{Publish your work in this journal}

Clinical Ophthalmology is an international, peer-reviewed journal covering all subspecialties within ophthalmology. Key topics include: Optometry; Visual science; Pharmacology and drug therapy in eye diseases; Basic Sciences; Primary and Secondary eye care; Patient Safety and Quality of Care Improvements. This journal is indexed on

\section{Dovepress}

PubMed Central and CAS, and is the official journal of The Society of Clinical Ophthalmology (SCO). The manuscript management system is completely online and includes a very quick and fair peer-review system, which is all easy to use. Visit http://www.dovepress.com/ testimonials.php to read real quotes from published authors. 